\title{
Concept for the historic parks' tactile maps development
}

\author{
Albina Mościcka ${ }^{\mathrm{a}, *}$, Jakub Wabiński ${ }^{\mathrm{a}}$, Andrzej Araszkiewicz ${ }^{\mathrm{a}}$, Marta Kuźma ${ }^{\mathrm{a}}$, Damian Kiliszek ${ }^{\mathrm{a}}$ \\ ${ }^{a}$ Military University of Technology, Warsaw,Poland, albina.moscicka@wat.edu.pl, jakub.wabinski@wat.edu.pl, \\ andrzej.araszkeiwicz@wat.edu.pl,marta.kuzma@wat.edu.pl,damian.kiliszek@wat.edu.pl \\ * Corresponding author
}

Keywords: thematic maps, tactile maps, blind and visually impaired, historic parks, garden styles, 3D printing

\begin{abstract}
:
The aim of the presented research is the development and pilot implementation of the technology of developing lowbudget tactile maps presenting cultural values of historic parks. Such maps increase the accessibility of the tourist and cultural offer for the blind and partially sighted. Previous maps of such parks are mainly situational or navigational maps, enabling only moving around the park. The novelty of the solutions is to convey the unique cultural values of park layouts by means of tactile maps presenting different park styles. A map can play such a role, as a composition covering a large area and containing an arrangement of specific elements of nature and architecture, juxtaposed with each other in such a way that they create a harmonious whole.
\end{abstract}

The research is carried out on the example of tactile maps for historic park layouts in 5 selected styles: Renaissance, Baroque, Sentimental, English and Japanese (Fig. 1). Each style has its own unique features, including spatial features. The map, as a reduced image of a fragment of the Earth, reflects the real relationships between objects located in space in a way that allows for comprehensive exploration of large areas. Therefore, it is an ideal tool for getting to know park layouts as a composition covering a large area. The methodically developed map of the park layout, through the appropriate selection of the content scope and the system of cartographic signs, conveys knowledge about the form, function and meaning of the element. small garden architecture, plant arrangements and garden arrangement compositions. The map will make it possible to learn about park compositions as a whole, thus providing a chance to get to know cultural goods that the blind or visually impaired people have not yet been able to fully experience in a direct way.

The idea of the research is to work out the principles of selecting and generalizing the content of tactile maps of parks, developing an original set of tactile and graphic signs and editing rules, as well as the method of preparing and printing tactile maps using modern low-cost printing techniques (e.g. 3D printing, swelling paper). The main challenge is to develop common set of cartographic signs for elements present in all park styles, and unique cartographic signs for the elements that distinguish them. It is very important for easy reception of the map content and better understanding of the cultural values transmitted by maps.

Moreover, innovative solutions consist in the use of additive printing techniques (3D) to reproduce maps for the blind. The use of this modern printing technique allows to print any designed 3D model. Therefore, unlike the previously used techniques of tactile map reproduction, our solutions enable the use of all haptic variables for the design of cartographic signs used on tactile maps. This means that we can freely design signs, including using their height differentiation, which was not possible before. Consequently, more information is conveyed than before with a single tactile cartographic sign. Moreover, by varying the height of the signs, we reduce the spacing between the tactile signs, while maintaining the readability of maps read by touch. As a result of the solutions we propose, more information can be placed on one map than was possible before. This is important because maps for the blind are highly generalized anyway, so the amount of content conveyed by tactile maps is very limited. Each increase in the amount of content conveyed through a single map is invaluable to the recipient. 


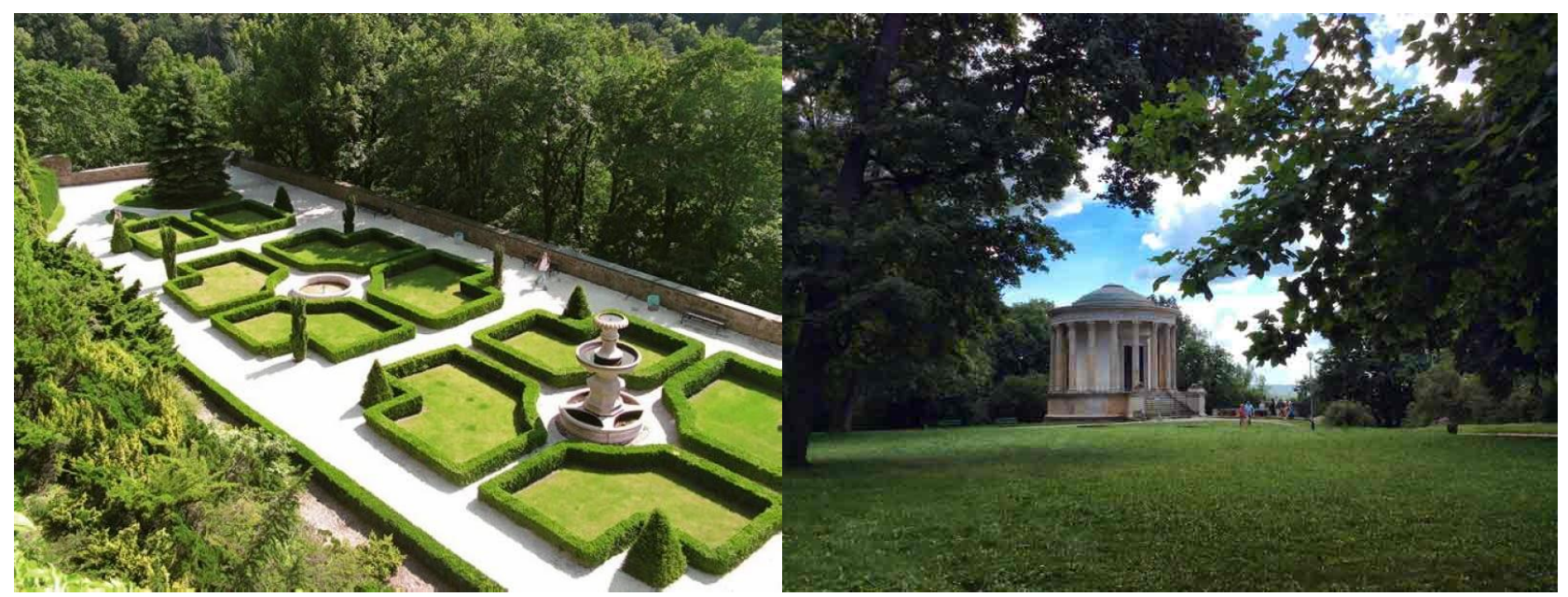

a) Renaissance style;

b) Sentimental style

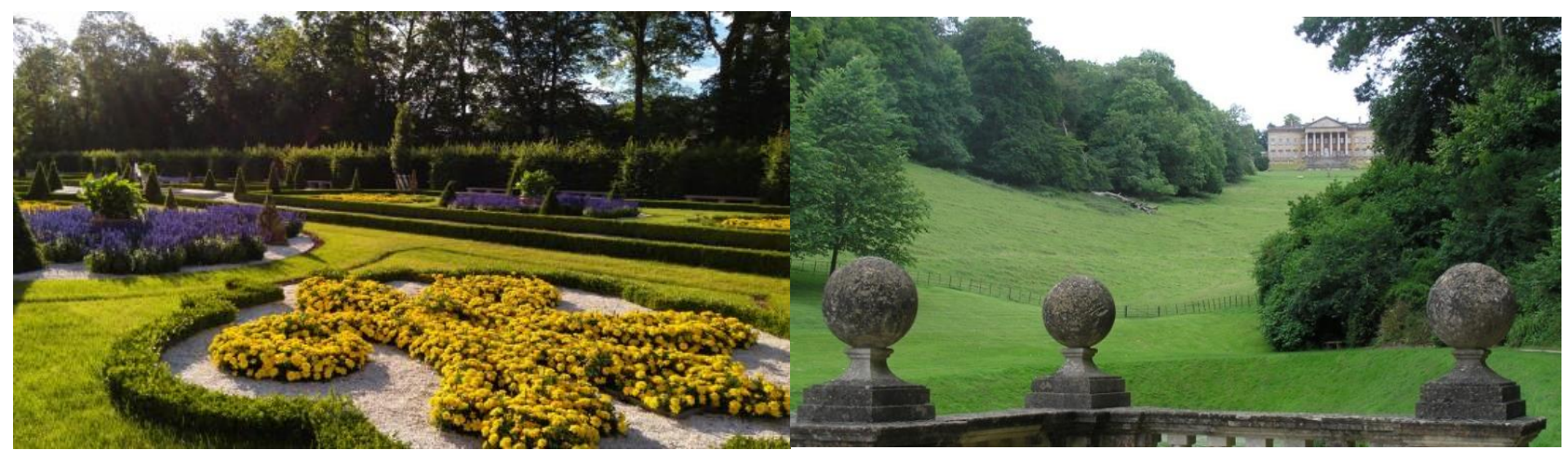

c) Baroque style;

d) English style

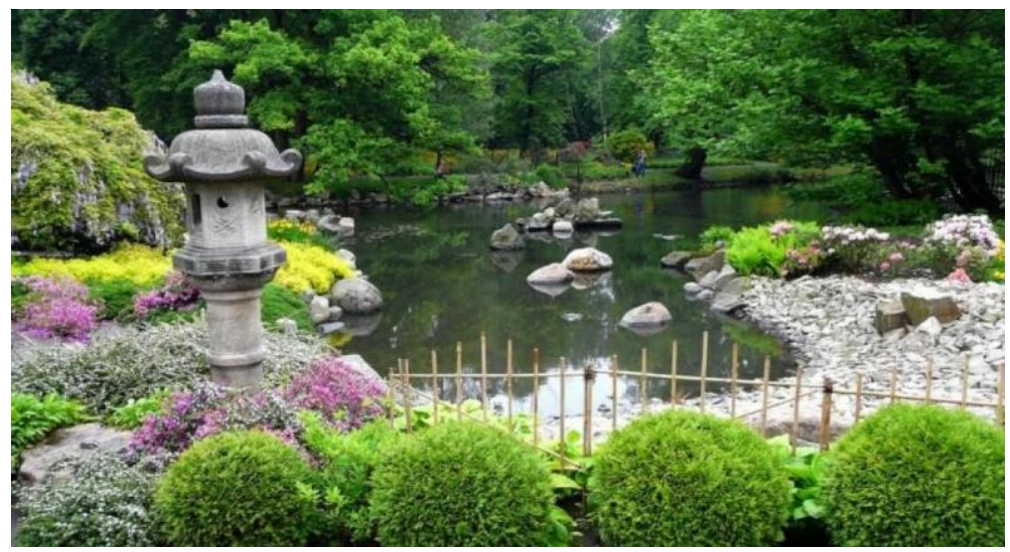

e) Japanese style

Figure 1. Different garden styles [1], [2], [3], [4], [5].

\section{References}

[1] https://ladnydom.pl/Ogrody/1,113379,8086702,Ogrody_tarasowe_zamku_w_Ksiazu.html

[2] https://www.gracetour.waw.pl/park-w-pulawach/

[3] https://www.wilanow-palac.pl/galeria/23208/7/foto/0

[4] http://ogrodtamaryszka.blogspot.com/2018/02/prior-park-landscape-garden.html

[5] https://www.polskieszlaki.pl/ogrod-japonski-we-wroclawiu.htm 